\title{
Accounting for spatial and temporal variation in macroinvertebrate community abundances when measuring the food supply of stream salmonids
}

\author{
Nicholas Weber ${ }^{1,4}$, Nicolaas Bouwes ${ }^{1,2,5}$, and Chris Jordan ${ }^{3,6}$ \\ ${ }^{1}$ Eco Logical Research, Inc., P.O. Box 706, Providence, Utah 84332 USA \\ ${ }^{2}$ Department of Watershed Sciences, Utah State University, 5210 Old Main Hill, Logan, Utah 84322 USA \\ ${ }^{3}$ National Oceanic and Atmospheric Administration Fisheries, Northwest Fisheries Science Center, Mathematical Ecology \\ and Systems Monitoring Program, 2725 Montlake Boulevard East, Seattle, Washington 98112 USA
}

\begin{abstract}
The goal of salmonid habitat monitoring programs is to measure habitat attributes linked to salmonid productivity based on protocols that have sufficient precision to detect environmental variation at relevant spatial and temporal scales. Benthic macroinvertebrate community composition often is evaluated as part of habitat monitoring and assessment protocols, despite a lack of direct relationships between benthic composition and salmonid production. Macroinvertebrate drift provides a direct measure of the food resources available to stream salmonids, but drift is rarely evaluated as part of habitat monitoring protocols. This reluctance may stem from the complex spatial and temporal variability inherent in macroinvertebrate drift abundances and an assumed inability to obtain precise estimates of drift abundance at relevant spatial and temporal scales. We evaluated an extensive set of paired drift and benthic macroinvertebrate samples to characterize variation in the biomass and density (i.e., counts) of macroinvertebrate samples across a hierarchy of spatial and temporal scales. Results suggest that estimates of total drift biomass may offer the most precise approach for detecting differences in salmonid food availability among stream reaches and, thus, may be more appropriate than benthic sampling for incorporation into salmonid habitat monitoring programs.
\end{abstract}

Key words: macroinvertebrate drift, food availability, habitat monitoring, salmonids, scale, stream macroinvertebrates

Monitoring programs designed to evaluate the status and trend of freshwater salmonid habitat are essential for the development of management and restoration practices capable of increasing the productivity of these culturally and economically important species. Monitoring programs must be based on protocols that are efficient, measure habitat attributes linked to salmonid productivity (i.e., survival, growth, reproduction), and do so with enough precision to detect environmental variation at relevant spatial and temporal scales (Roper et al. 2002, Larsen et al. 2004). Macroinvertebrates, specifically those entrained in the current as drift, are the primary supply of food for stream salmonids (Elliot 1970, 1973, Tippets and Moyle 1978, Cada et al. 1987). Many approaches have been developed for evaluating macroinvertebrate community composition as an indicator of water quality, ecosystem function, or deviation from reference con- ditions (Carter and Resh 2001, Bonada et al. 2006). These approaches often are implemented as part of salmonid habitat assessments (e.g., Downie 2004, Hillman 2006, Heitke et al. 2009, AREMP 2013), but direct relationships between benthic macroinvertebrate community composition and the productivity of salmonids are not well established (Fausch et al. 1988).

Samples used to evaluate benthic macroinvertebrate community composition are collected using kick-net or Surber type equipment with the intent of gathering a comprehensive sample of the taxa residing in the substrate. However, many benthic macroinvertebrate taxa possess behavioral or life-history characteristics that limit their propensity to enter the drift and are rarely available to salmonids as prey (Tippets and Moyle 1978, Rader 1997, Poff et al. 2006). In contrast, macroinvertebrate drift provides a more

E-mail addresses: ${ }^{4}$ nick.weber@ecologicalresearch.net; ${ }^{5}$ nbouwes@ecologicalresearch.net; ${ }^{6}$ chris.jordan@noaa.gov

DOI: 10.1086/692012. Received 22 April 2016; Accepted 31 January 2017; Published online 5 April 2017.

Freshwater Science. 2017. 36(2):364-376. () 2017 by The Society for Freshwater Science. 
direct measure of food resource availability (De Crespin De Billy et al. 2002), and includes terrestrial sources of prey that make a substantial contribution to the diet of drift-feeding salmonids (Wipfli and Baxter 2010). Nevertheless, macroinvertebrate drift abundance (i.e., drift density [individuals/ $\mathrm{m}^{3}$ ] or biomass $\left[\mathrm{mg} / \mathrm{m}^{3}\right]$ ) rarely is measured in habitat monitoring and assessment programs aimed at describing factors affecting freshwater salmonid productivity. This omission may stem from spatial and temporal variation inherent in patterns of drift (Brittain and Eikeland 1988, Naman et al. 2016), the complexity of which may have hindered the development of efficient sampling designs that yield precise estimates of drift abundances (Elliot 1973, Allan 1987).

Macroinvertebrates enter the drift passively and actively in response to environmental and behavioral factors that give rise to the complex spatial and temporal patterns exhibited by drift abundance (Waters 1972, Muller 1974, Shearer et al. 2002, Malmqvist 2002). Diel periodicity, characterized by low drift during the day and increased drift during crepuscular and low-light periods at night (Waters 1962), serves as a prime example of this complexity and is thought to be a means by which macroinvertebrates avoid predation by sight-feeding fishes during dispersal (Allan 1978, Flecker 1992). Emergence of aquatic taxa in response to environmental factors, such as changing weather, stream temperature, or light conditions also may trigger active entry into the drift, causing variation in drift abundance at temporal scales ranging from hours to seasons (Malmqvist 2002, Hansen and Closs 2006). Accidental entry into the drift often is associated with fluctuations in discharge that dislodge macroinvertebrates from the stream bed or as bed materials become actively transported (Poff and Ward 1991, Gibbins et al. 2007). Benthic macroinvertebrate community composition also affects how temporal patterns in macroinvertebrate drift are likely to be expressed. Taxon-specific life-history and behavioral traits related to habitat choice, emergence behavior, and developmental timing all affect the propensity for macroinvertebrates to become entrained in the drift (Rader 1997).

Benthic macroinvertebrate community structure is influenced by biotic and abiotic processes that manifest across spatial and temporal scales (Boyero 2003, Parsons et al. 2003). Variation in stream temperature, discharge, nutrient availability, sediment dynamics, and the composition of riparian vegetation can influence the distribution of stream macroinvertebrates. These features of stream environments are determined at regional scales by climatic conditions and at the catchment or watershed scale by elevation, drainage area, and geology (Whittier et al. 1988, Li et al. 2001). At the scale of streams or stream reaches, benthic macroinvertebrate composition will be subject to riparian vegetation characteristics that alter the infiltration of sunlight and availability of allochthonous material (Hawkins et al. 1983). Local variation in velocity and bed material among distinct geomorphic units will further influence the composition of benthic macroinvertebrate communities.

Identifying the scale at which organisms and environmental characteristics exhibit and respond to variation is important to understanding ecological interactions (Wiens 1989), such as the relationship between salmonids and their habitat (Folt et al. 1998). In addition, a multiscale framework describing environmental and organismal heterogeneity is essential for developing sampling designs that capture ecological processes at appropriate and practical spatial and temporal scales (Palmer et al. 1997). Drift-foraging salmonids may adjust their foraging rate and location to exploit smallscale spatial and temporal variation in abundance of drifting macroinvertebrates, such as among velocity gradients or in response to diel fluxes in drift abundances (Elliot 1970, Nislow et al. 1999). However, characterizing variation in macroinvertebrate drift abundance at this level of resolution may require sampling designs that are beyond the scope of regional salmonid habitat assessment studies designed to prioritize conservation and restoration strategies. In streams, distances from $100 \mathrm{~m}$ to several kilometers may be the most feasible and common spatial scale of observation for use in regional salmonid habitat monitoring and assessment programs, and results of field studies have demonstrated relationships between food availability measured as drifting or benthic macroinvertebrate abundance and salmonid growth rates (Weber et al. 2014), habitat selection (Nislow et al. 1998), and population density (Urabe et al. 2010).

We collected an extensive set of paired drifting and benthic macroinvertebrate samples to characterize the relative variation in the biomass and density (i.e., counts) of macroinvertebrate communities across a hierarchy of spatial and temporal scales. We used this information to compare the precision of each sampling method and measure of macroinvertebrate abundance to identify the most efficient approach for detecting variation at a relevant and practical scale. The results of our study could be used in the development of sampling designs that can be incorporated into regional monitoring and assessment protocols for describing salmonid food resource availability and could aid in the immediate task of increasing our understanding of factors limiting the freshwater productivity of salmonid populations.

\section{METHODS \\ Study area}

We collected macroinvertebrate samples among 10 reaches within 6 streams in the John Day River Basin in central Oregon, USA (Fig. 1A-D). This region is characterized by a semi-arid continental climate with broad seasonal swings in air temperature from hot summers to cold winters. Snow accumulations at higher elevations during winter strongly influence annual hydrographs. Peak discharge occurs during spring snowmelt, and flows recede to low baseflow discharge by early summer. 


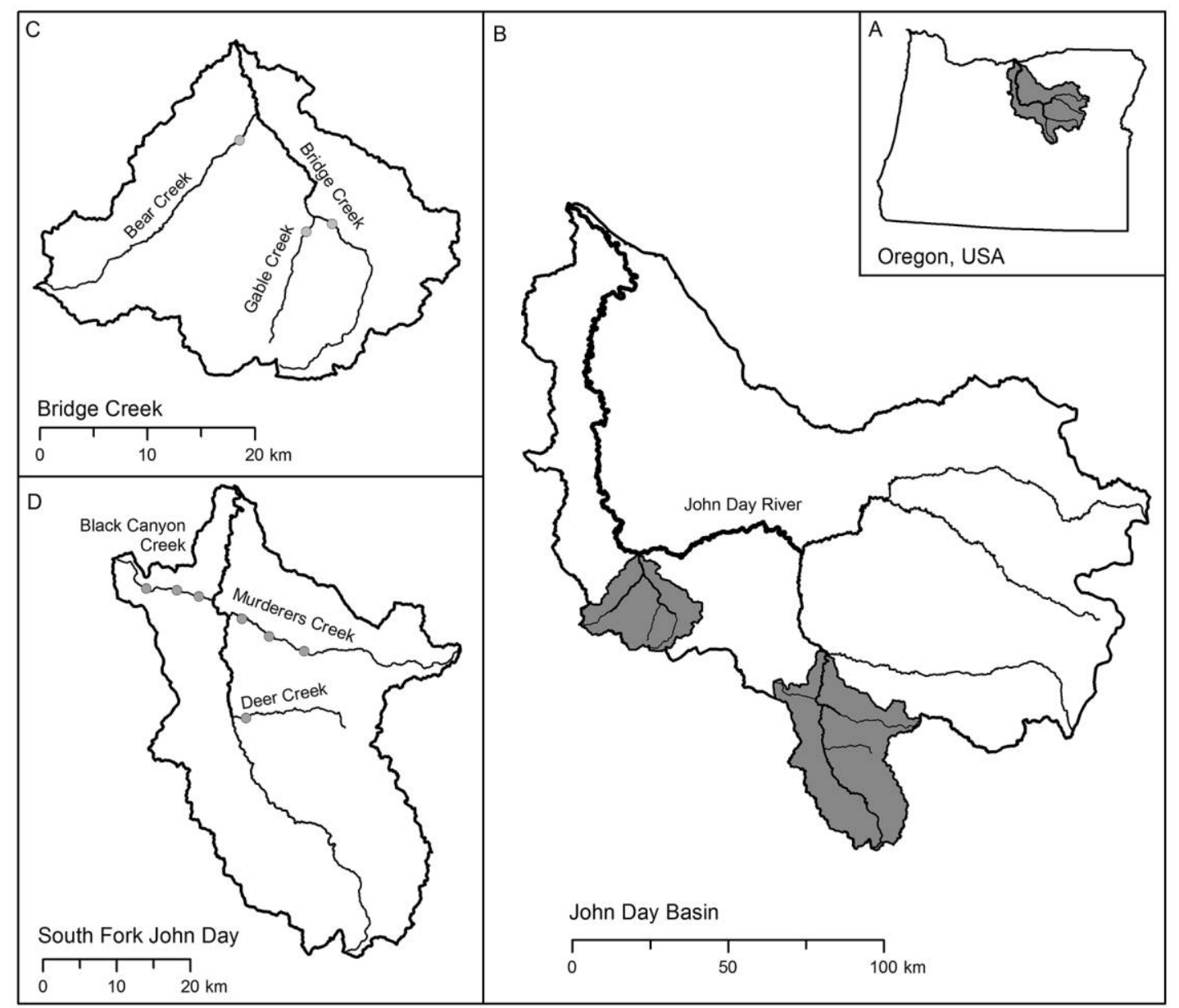

Figure 1. Map of the study area showing the John Day Basin in Oregon, USA (A), location of study sub-basins (B), and primary study streams within the Bridge Creek (C) and South Fork John Day sub-basins (D). Gray dots show the locations of study reaches.

Study reaches could all be characterized as small, wadeable stream channels with baseflow wetted channel widths between 2.1 and $5.7 \mathrm{~m}$ (Table 1). Typical depths ranged between 0.05 and $0.3 \mathrm{~m}$ in fast-water channel units, and up to $0.5 \mathrm{~m}$ in slow-water pools. A range of elevations and catchment characteristics contribute to physical and biological contrasts among study sites. Lower-elevation sites (BE1, BR1, GC1, MC1, MC2) flow through open-canopy valley bottoms dominated by juniper (Juniperus sp.), sagebrush (Artemisia sp.), and upland grasses. Sites at mostly higher elevations $(\mathrm{BC} 1, \mathrm{BC} 2, \mathrm{BC} 3, \mathrm{DC} 1, \mathrm{MC} 3)$ were more characteristic of a confined valley setting with an overstory of ponderosa pine (Pinus ponderosa), lodgepole pine (Pinus contorta), and various species of fir (Abies sp.). Woody riparian vegetation at all study sites consists of willow (Salix sp.), alder (Alnus sp.), and red-osier dogwood (Cornus sericea). Stream temperatures are correlated with elevation. Maximum daily temperatures are regularly $>20^{\circ} \mathrm{C}$ at the lowest elevations, and temperatures are cooler at higher elevation sites (Table 1).

\section{Macroinvertebrate sampling}

We collected macroinvertebrate samples based on a multiscaled design with the specific goal of characterizing the variance in macroinvertebrate community abundance and composition across space and time (Fig. S1). We collected all samples during a single summer between 23 June and 29 August 2006 when study streams were at or near low baseflow conditions (Table 1). We sampled a total of 10 reaches distributed among 6 streams (Figs 1A-D, S1). Two streams, Murderers Creek and Black Canyon Creek each contained 3 sampling reaches separated by $\sim 2 \mathrm{~km}$. We sampled drift during 4 biweekly visits to each reach in late June, middle July, early August, and late August by placing 2 nets over a cross-section of the stream channel in locations where they could capture the greatest percentage of the total stream discharge. In most cases, each visit consisted of sampling drift over a single 24-h period (day) by deploying between 3 and 8 pairs of nets for durations of 3 and 8 h. However, at 3 reaches, we collected drift in the same manner over 3 consecutive days and simultaneously at 3 riffle units 
Table 1. Minimum and maximum discharge, mean channel width, elevation, minimum (min) and maximum (max) temperature, and number of drift and benthic samples collected among reaches during the study.

\begin{tabular}{llcccccc}
\hline \multicolumn{1}{c}{ Stream } & Reach & $\begin{array}{c}\text { Discharge } \\
\left(\mathrm{m}^{3} / \mathrm{s}\right)\end{array}$ & $\begin{array}{c}\text { Channel } \\
\text { width }^{\mathrm{b}}(\mathrm{m})\end{array}$ & $\begin{array}{c}\text { Elevation } \\
(\mathrm{m})\end{array}$ & $\begin{array}{c}\text { Temperature min, } \\
\text { mean, max }^{\mathrm{c}}\left({ }^{\circ} \mathrm{C}\right)\end{array}$ & $\begin{array}{c}\text { Drift } \\
\text { samples }\end{array}$ & $\begin{array}{c}\text { Benthic } \\
\text { samples }\end{array}$ \\
\hline Bear Creek & $\mathrm{BE} 1$ & $0.10-0.03$ & 2.2 & 618 & $15.5,19.6,24.8$ & 12 & 2 \\
Black Canyon Creek & $\mathrm{BC} 1$ & $0.51-0.28$ & 3.9 & 917 & $13.7,16.9,20.8$ & 58 & 6 \\
& $\mathrm{BC} 2$ & $0.36-0.22$ & 5.7 & 995 & $12.6,15.4,18.7$ & 21 & 2 \\
Bridge Creek & BC3 & $0.37-0.21$ & 4.6 & 1130 & $11.6,13.4,15.3$ & 21 & 2 \\
Deer Creek & BR1 & $0.47-0.27$ & 3.3 & 734 & $13.4,17.0,21.0$ & 12 & 2 \\
Gable Creek & DC1 & $0.13-0.04$ & 2.7 & 1060 & $13.7,16.2,19.2$ & 34 & 6 \\
Murderers Creek & GC1 & $0.38-0.06$ & 2.1 & 729 & $13.3,16.9,21.9$ & 12 & 2 \\
& MC1 & $0.49-0.17$ & 4.2 & 920 & $18.1,22.4,27.4$ & 20 & 2 \\
& MC2 & $0.41-0.13$ & 3.6 & 977 & $15.8,20.3,24.8$ & 44 & 6 \\
\hline
\end{tabular}

\footnotetext{
${ }^{\text {a }}$ Measured at each reach on each drift sample collection date using methods published by Peck et al. (2006)

b Taken as the mean of the wetted channel width measurements from discharge cross-sections

${ }^{\mathrm{c}}$ Measured using temperature loggers (U22-001; Onset, Bourne, Massachusetts) anchored in the wetted channel for the duration of the study
}

separated by distances of 100 to $150 \mathrm{~m}$. This design resulted in 41 total days of drift sampling and 253 individual drift samples.

Drift nets had a mouth opening $40 \mathrm{~cm}$ high $\times 20 \mathrm{~cm}$ wide and were composed of $1-\mathrm{mm}$ Nitex ${ }^{\circledR}$ mesh. The top of the net mouth always protruded above the water surface to capture terrestrial and emerging aquatic macroinvertebrates, and the bottom was suspended $\sim 2 \mathrm{~cm}$ above the channel bed to prevent macroinvertebrates from crawling into nets. Flow velocity entering drift nets was measured at the center of the submerged portion of the net mouth with a Global Water ${ }^{\circledR}$ velocity meter (FP111; Global Water, College Station, Texas). The total volume of water sampled during each net deployment $\left(\mathrm{m}^{3}\right)$ was estimated by multiplying the area of the net mouth submerged by the mean of flow velocity entering the net measured at the beginning and end of each deployment and by sample duration (Allan and Russek 1985, Matthaei et al. 1998).

We sampled benthic macroinvertebrates with a similar but reduced design that did not include multiple samples within riffles or days or among consecutive days. We collected benthic samples by thoroughly disturbing the substrate enclosed within a $0.09-\mathrm{m}^{2} 500-\mu \mathrm{m}$ Nitex ${ }^{\circledR}$ mesh Surber sampler at 8 randomly selected locations within a single riffle unit. We pooled the 8 Surber collections as a single sample. We sampled each of the 10 reaches during 2 occasions in middle July and early August. At 3 of the reaches, we sampled 3 distinct riffles separated by 100 to $150 \mathrm{~m}$ during each of 2 visits. This design led to collection of 32 benthic samples.

We preserved macroinvertebrate samples in $70 \%$ ethanol in the field and transported them to a laboratory for processing. We separated organisms from organic material and identified them to a relevant taxonomic level (Merritt and Cummins 1995), usually family, and assigned them to groups based on taxa, life-history stage, and terrestrial or aquatic origin for enumeration and weighing. We grouped aquatic macroinvertebrates according to 5 orders (Coleoptera, Diptera, Ephemeroptera, Plecoptera, Trichoptera) and a $6^{\text {th }}$ composite group of taxa belonging to other orders. We counted and weighed emergent aquatic adult life-stages (e.g., adult Ephemeroptera) and terrestrial macroinvertebrates in drift samples separately. We dried groups for $\geq 24 \mathrm{~h}$ at $60^{\circ} \mathrm{C}$ until they reached constant mass and measured dry mass to the nearest mg for each group. We divided raw counts and measures of dry mass for macroinvertebrates in drift samples by the volume of water sampled by each net and multiplied by 100 to calculate drift density (individuals [ind] $\left./ 100 \mathrm{~m}^{3}\right)$ and biomass $\left(\mathrm{mg} / 100 \mathrm{~m}^{3}\right)$. We calculated benthic density (ind $/ \mathrm{m}^{2}$ ) and biomass $\left(\mathrm{mg} / \mathrm{m}^{2}\right)$ by dividing organism counts and masses by total area sampled.

\section{Variation in macroinvertebrate abundances}

We used a series of mixed-effect analysis of variance (ANOVA) models to estimate variation among samples of total drift and benthic density and biomass attributable to each temporal or spatial scale. Spatial and temporal factors were treated as nested random effects to capture the hierarchical structure of the sampling design. Model specifications for drift samples included 7 nested factors (streams, reaches within streams, weeks within reaches, riffles within weeks, days within riffles, time of day within days, and nets). Model specifications for benthic samples included 4 nested factors (streams, reaches in streams, weeks in reaches, riffles in weeks). Mixed-effect ANOVAs were run in the R envi- 
ronment for statistical computing (version 3.2.1; R Project for Statistical Computing, Vienna, Austria) with the nlme package (Bates 2010). All modeling was conducted using raw values of drift and benthic density and biomass because model residuals were approximately normal.

We used variance estimates to calculate the proportion of the total variation attributable to each spatial and temporal scale for drift and benthic biomass and density. Much of the variance for drift samples was associated with nets (i.e., channel position) and time of day. In the interest of alleviating some of this variation, we produced additional aggregated calculations of drift density and biomass by pooling the total volume of water and macroinvertebrates sampled by each net (within a cross section) over each 24-h period, much like pooling separate benthic Surber collections as a single aggregate sample. Aggregating the drift data reduced the size of the data set to 63 samples, where each sample represented pairs of drift nets sampled over a 24-h period. We used the aggregated drift data to estimate variance components and \% variance in drift abundances for the remaining spatial and temporal factors (streams, reaches within streams, weeks within reaches, riffles within weeks, days within riffles).

We also used variance estimates from the mixed-effects model to calculate the signal-to-noise ratio $(S: N)$ and coefficient of variation (CV) as additional measures of the precision associated with estimates of total drift and benthic density and biomass. S: Ns reflect the ability of a sampling method to detect variability at a scale of interest relative to variability considered sampling noise. We calculated $S: N$ with respect to streams and reaches by dividing their variance estimates by the sum of all other variance components considered noise (i.e., weeks, riffles, days, time of day, nets). We also calculated the CV for each metric of macroinvertebrate sampling abundance relative to the stream and reach scale. We calculated CV by dividing the square root of the sum of variance considered sampling noise by the grand mean of macroinvertebrate abundances estimated by the mixedeffects model (i.e., model intercept) and multiplied by 100 . We estimated $\mathrm{S}$ : Ns and CVs based on the aggregated calculations of drift abundance. S:Ns and CVs were used to evaluate the precision of macroinvertebrate abundance estimates relative to other attributes commonly measured as part of salmonid habitat assessments (Kaufmann et al. 1999, Roper et al. 2010). These guidelines interpret the precision of attributes with values of $\mathrm{S}: \mathrm{N}<2.5$ as low, 2.5 to 6.5 as moderate, and $>6.5$ as high. The precision of metrics with a CV $<20 \%$ is interpreted as high, 20 to $35 \%$ as moderate, and $>35 \%$ as low.

\section{Drift sampling precision and effort}

We put our estimates of precision into an applied context by estimating the number of samples that would be required to detect statistically significant differences or to achieve confidence intervals (CIs) within a percentage of the mean for drift density and biomass at the reach scale. We calculated both sample size estimates relative to the grand mean of drift density $\left(29.73 \mathrm{ind} / 100 \mathrm{~m}^{3}\right)$ and biomass $\left(27.99 \mathrm{mg} / 100 \mathrm{~m}^{3}\right)$ estimated by the mixed-effects models (i.e., intercept term) for the aggregated drift sample data. We calculated sample sizes based on the highest and lowest estimate of variance around the mean from all drift samples collected at each reach. We estimated the number of samples needed to detect a statistically significant difference in the grand mean with a $t$-test (Zar 1999) for differences from 25 to $200 \%$. For each sample-size estimate we set $\alpha=0.05$ and the power of the test $=0.80$. The number of samples needed to obtain $95 \%$ CIs within a percentage of the grand mean was estimated from 10 to $100 \%$.

\section{RESULTS}

\section{Macroinvertebrate abundance and composition}

Total drift biomass and density remained relatively constant during the summer sampling season but showed a slight increase as summer progressed (Fig. 2A, D). Drift abundances during the day and night varied substantially, with an average of 19.3 and 14.6 during the day and 39.3 and 37.2 during the night for density (ind $/ 100 \mathrm{~m}^{3}$ ) and drift biomass $\left(\mathrm{mg} / 100 \mathrm{~m}^{3}\right)$, respectively (Fig. $\left.2 \mathrm{~B}, \mathrm{E}\right)$. Considerable variation in mean drift abundances also was apparent among streams, and in several cases, mean drift biomass and density varied by several fold (Fig. 2C, F).

Aquatic macroinvertebrate larvae belonging to Diptera, Ephemeroptera, Plecoptera, Trichoptera, and Coleoptera (adults and larvae) made up the greatest portion of drift density and biomass (Fig. 2A-F, Table S1). Larval dipterans made up a small proportion of total drift biomass (1-3\%), but were more represented in drift density, especially in 2 low-elevation streams (Bear and Gable Creeks). The proportion of total drift density composed of Diptera also increased steadily from early to late summer. Drifting Diptera consisted primarily of Chironomidae and Simuliidae. Drifting Ephemeroptera, mainly baetids, also increased in abundance over the summer. Plecoptera, which was composed primarily of Perlidae, Perlodidae, and Nemouridae, made up a very small proportion (1-4\%) of total drift density and biomass. Macroinvertebrates not belonging to these major orders generally accounted for a small portion of total drift abundance, but amphipods and annelids occurred in the drift with some consistency.

Emergent adult life-stages of aquatic macroinvertebrates, largely Ephemeroptera and Diptera, were common in the drift and, in some streams, accounted for almost $50 \%$ of total drift density (Fig. 2C, Table S1). Terrestrial macroinvertebrates were common in the drift and, on average, accounted for 4 to $21 \%$ and 11 to $35 \%$ of drift density and biomass, respectively, among streams (Fig. 2C, F). Drifting 

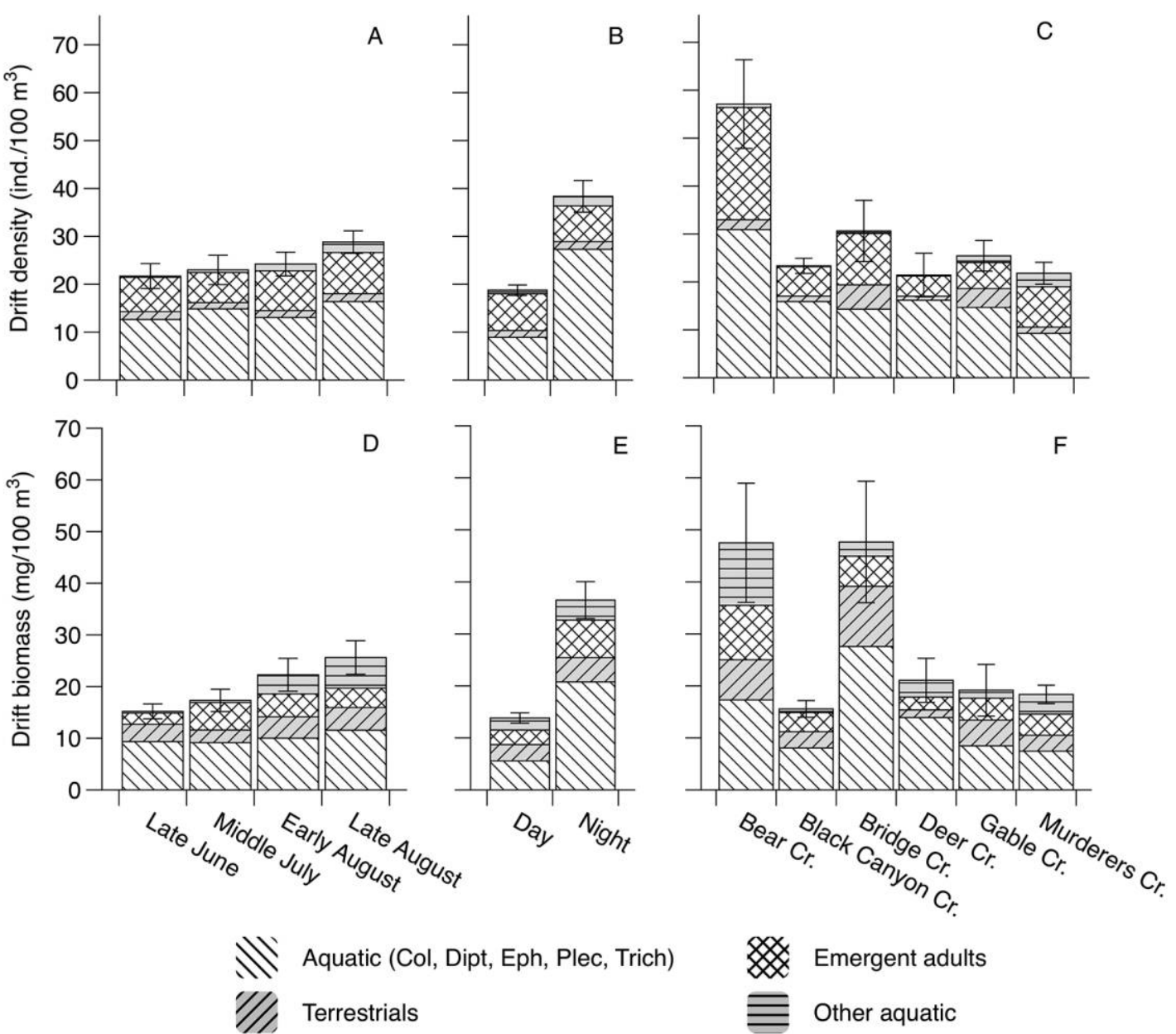

Figure 2. Mean $( \pm \mathrm{SE})$ total drift density $(\mathrm{A}-\mathrm{C})$ and biomass $(\mathrm{D}-\mathrm{F})$ and composition by major taxonomic group among bi-weekly sampling periods (A, D), between day and night $(B, E)$, and among study streams $(C, F)$. Col $=$ Coleoptera, Dipt $=$ Diptera, Eph $=$ Ephemeroptera, Plec $=$ Plecoptera, Trich $=$ Trichoptera, Ind. $=$ individuals, Cr. $=$ Creek.

terrestrial macroinvertebrates were primarily hymenopterans and hemipterans.

Benthic density increased from a mean of roughly 1500 to $2000 \mathrm{ind} / \mathrm{m}^{2}$ from mid-July to early August, whereas benthic biomass remained relatively consistent at $1250 \mathrm{mg} / \mathrm{m}^{2}$ during the study period (Fig. 3A, C). Total benthic density and biomass also exhibited considerable variation among streams, with mean density ranging from 1230 to $4520 \mathrm{ind} / \mathrm{m}^{2}$ and biomass from 610 to $2580 \mathrm{mg} / \mathrm{m}^{2}$ (Fig. 3B, D). The composition of benthic samples appeared to remain relatively consistent throughout the study period, but was more spatially variable among streams (Table S2, Fig. 3B, D). Trichoptera, which were numerically dominated by Hydropsychidae, made up a substantial proportion of biomass among all streams. Coleoptera (largely larvae and adults of Elmidae) accounted for $\leq 34 \%$ of benthic density and $\leq 12 \%$ of biomass among streams. On Bridge Creek, Diptera comprised Diptera Chironomidae, Simuliidae, and Tipulidae, which together made up $42 \%$ of benthic density. Baetidae and Heptageniidae accounted for most Ephemeroptera in benthic samples, and Plecoptera comprised primarily Perlidae and Perlodidae. Other orders (annelids and mollusks) made minor contributions to total benthic density and biomass.

\section{Variation in macroinvertebrate abundance}

Mixed-effects models attributed much of the variation in samples of macroinvertebrate drift to time of day and channel position between nets (Table 2). When combined, these small temporal and spatial scales accounted for $61 \%$ of the total variance in drift density and $70 \%$ in drift biomass. Variance among streams accounted for much of the remaining variance in samples of drift density (28\%) and biomass (30\%). Aggregating drift samples within days and among replicate nets shifted much of the variation in drift density and biomass to target spatial scales of streams and stream reaches. Most variance in the aggregated calculation 

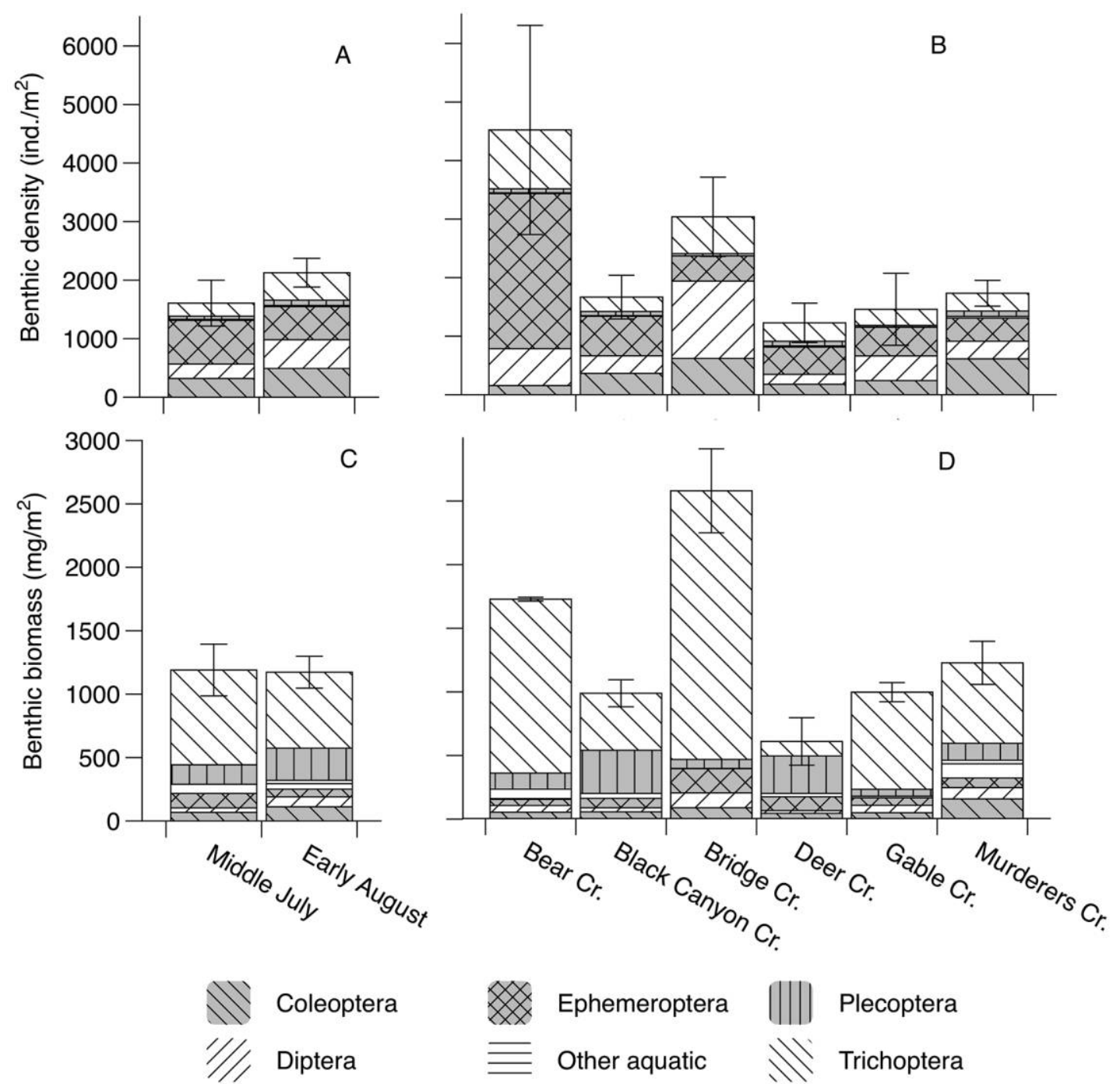

Figure 3. Mean $( \pm$ SE) benthic density $(A, B)$ and biomass $(C, D)$ for major orders of macroinvertebrates calculated between biweekly sampling periods (A, C) and among study streams (B, D). Ind. = individuals, Cr. = Creek.

of drift abundances was among streams, which accounted for $78 \%$ of the total variance in drift biomass and $50 \%$ in drift density. Variation among weeks was greater for drift density (19\%) than biomass (3\%). Variation among riffles within reaches was low, regardless of the measure of drift abundance. Variation among consecutive days accounted for more of the total variance in aggregated drift density (31\%) than biomass (8\%). The variance estimate for drift density and biomass among reaches within streams was $0 \%$. Some amount of variance probably exists at this spatial scale, but it did not warrant incorporating an additional random effect in the model (Bates 2010).

The distribution of variance in samples of benthic abundance followed a pattern similar to that of the aggregated drift data. Variance among streams accounted for $50 \%$ of the total variance in samples of benthic density and $56 \%$ for benthic biomass. Variance among reaches within streams was greater for biomass (22\%) than benthic density (0\%). In contrast to drift, variance among riffles within reaches was considerable for benthic density (46\%) and biomass (22\%).

Total drift biomass had the highest $\mathrm{S}: \mathrm{N}$ among streams (3.7), suggesting a moderate precision and ability to detect environmental variation at relevant scales (Table 3). Estimates of benthic biomass also had a low value of $S: N(2.6)$ among reaches. $\mathrm{S}: \mathrm{N}$ for other estimates of abundance and scale contrasts were low (i.e., $\mathrm{S}: \mathrm{N}<2.5$ ). $\mathrm{CV}$ told a similar story, with estimates of macroinvertebrate densities having a low sampling precision relative to the mean (i.e., $\mathrm{CV}>$ $35 \%)$. Drift biomass had the highest precision (28\%) among streams, suggesting moderate precision at this spatial scale. Values of $\mathrm{S}: \mathrm{N}$ and $\mathrm{CV}$ suggested that estimates of drift and benthic biomass were generally more precise than density. 
Table 2. Percent of total variance estimated by mixed-effects analysis of variance models among spatial and temporal scales for samples of drift and benthic density and biomass. Pooled $=$ spatial and temporal scales aggregated within the drift data, na $=$ scale not represented in benthic sampling design.

\begin{tabular}{llccccccc}
\hline Sample type & \multicolumn{1}{c}{ Measure } & Streams & $\begin{array}{c}\text { Reaches } \\
\text { (within stream) }\end{array}$ & Weeks & Riffles & Days & Within day & Nets \\
\hline Drift & Density & 28 & 0 & 11 & 0 & 0 & 42 & 19 \\
& Biomass & 30 & 0 & 0 & 0 & 0 & 28 & 42 \\
& Density-aggregated & 50 & 0 & 19 & 0 & 31 & pooled & pooled \\
& Biomass-aggregated & 78 & 0 & 3 & 11 & 8 & pooled & pooled \\
Benthic & Density & 50 & 0 & 4 & 46 & na & na & na \\
& Biomass & 56 & 22 & 0 & 22 & na & na & na \\
\hline
\end{tabular}

\section{Drift sampling precision and effort}

At the reach scale, drift biomass had higher precision indices $(S: N, C V)$ than drift density, so fewer samples were needed to detect significant differences or to quantify mean drift with a high degree of precision (Fig. 4A, B). This analysis demonstrated that small changes in mean drift abundance would be difficult to detect unless sample variance was low or many samples were collected. For example, at the highest variance observed for drift biomass, detecting a $25 \%$ increase in the mean among reaches would require collection of $>20$ drift samples. In contrast, even when sample variance is high, a $100 \%$ difference in drift density could be detected with 6 samples, and the same difference in drift biomass could be detected with only 4. Similarly, when sample variances are high, obtaining 95\% CIs within $25 \%$ of the mean would require $>10$ samples of drift biomass and $>20$ samples of drift density. More modest precision, such as CIs within $50 \%$ of the mean would require as few as 5 samples of drift biomass and 8 samples of drift density even at the highest level of variance observed around the mean.

\section{DISCUSSION}

We demonstrated that variation in macroinvertebrate abundances tend to be most pronounced at the scale of streams and stream reaches (Tables 2, 3), a spatial scale that is relevant to studies of salmonid populations and often the scale of assessment in regional salmonid habitat monitoring programs. By comparing the variation among different macroinvertebrate sampling approaches (i.e., benthic and drift) and measures of abundance (i.e., density and biomass), we showed that macroinvertebrate drift biomass, a measure of invertebrate abundance that has direct relevance as available food (Weber et al. 2014), has the highest precision at the reach scale. These observations of macroinvertebrate community variation can be used to develop efficient approaches for measuring the food supply of stream salmonids.

\section{Macroinvertebrate abundance and composition}

Mean drift abundances at the reach scale (Table S1, Fig. 2A, D) spanned a 3-fold range for total density (14.9-

Table 3. Percent of total variance, signal-to-noise ratio $(S: N)$, and coefficient of variation (CV) calculated for measures of total drift and benthic density and biomass among streams and stream reaches.

\begin{tabular}{llllll}
\hline \multirow{2}{*}{ Measure } & \multirow{2}{*}{$\begin{array}{c}\text { Scale of } \\
\text { interest (signal) }\end{array}$} & \multicolumn{2}{c}{ \% variance } & & \\
\cline { 3 - 4 } Drift density & Signal & Noise & & S:N & CV (\%) \\
\hline \multirow{3}{*}{ Drift biomass } & Streams & 56 & 44 & Low (1.3) & Low (37) \\
& Reach & 43 & 57 & Low (0.8) & Low (39) \\
Benthic density & Streams & 79 & 21 & Moderate (3.7) & Moderate (28) \\
& Reach & 70 & 30 & Low (2.3) & Moderate (33) \\
Benthic biomass & Streams & 50 & 50 & Low (1.0) & Low (47) \\
& Reach & 28 & 72 & Low (0.4) & Low (56) \\
& Streams & 69 & 31 & Low (2.3) & Moderate (32) \\
& Reach & 72 & 28 & Low (2.6) & Moderate (30)
\end{tabular}




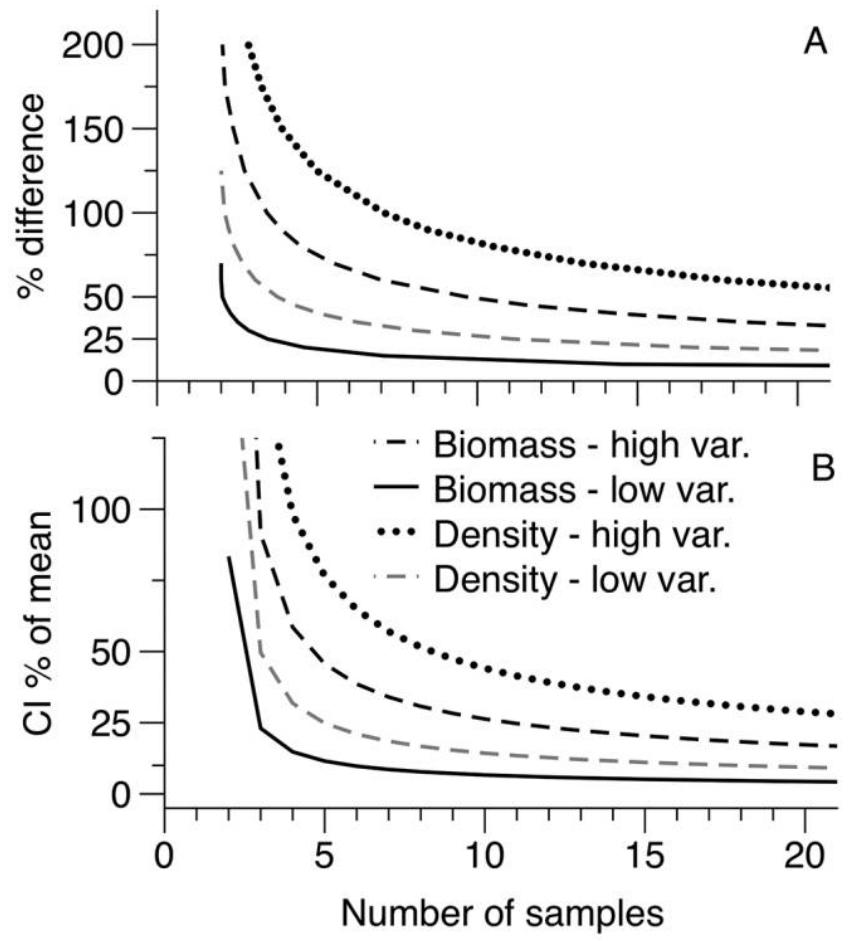

Figure 4. Number of drift samples needed to detect differences in the mean (A) and to achieve confidence intervals (CIs) within a given percentage of the mean (B) of total drift density and biomass. Var. $=$ variance.

$57.1 \mathrm{ind} / 100 \mathrm{~m}^{3}$ ) and 4-fold range for total biomass (11.9$47.7 \mathrm{mg} / 100 \mathrm{~m}^{3}$ ). While several-fold differences in drift may appear broad, authors of other drift studies have reported mean total drift density spanning orders of magnitude over time periods similar those in our study (Allan and Russek 1985, Neale et al. 2008). A low range of mean drift abundance contributed to the low variance estimated among streams and reaches in relation to other factors of temporal and spatial variance. This low range may have placed a ceiling on $\mathrm{S}: \mathrm{N}$ estimates and perceived ability to detect variation at target spatial scales. If a similar study were repeated encompassing reaches with a greater range of drift abundances, $\mathrm{S}$ : Ns probably would be greater.

Despite a several-fold difference in drift abundance among reaches, total drift density and biomass remained relatively constant during the summer study period (Fig. 2A, D). This temporal consistency was supported by the variance decomposition in which only $19 \%$ of the variance in drift density and $3 \%$ of variance in biomass were attributable to intraseasonal variation among weeks. Total drift remained relatively constant, but taxonomic composition showed considerable variation within season (Table S1). For example, the abundance of Trichoptera and Coleoptera in the drift tended to decrease whereas Ephemeroptera and Diptera increased steadily throughout the summer. Differential trends in the contribution of various taxa will have a compensatory effect, resulting in intraseasonal consistency in total drift abundance. This phenomenon probably is a result of life-history and developmental differences among taxa that affect propensity and timing of drift entry (Rader 1997).

Emerging adult life-stages of aquatic macroinvertebrates made substantial contributions to total drift, accounting for $50 \%$ of drift density and up to $25 \%$ of drift biomass in some reaches (Table S1, Fig. 2A-F). Without exception, terrestrial macroinvertebrates also made substantial contributions to total drift abundance throughout the duration of the study period. Terrestrial macroinvertebrates are an important prey subsidy for stream salmonids (Cada et al. 1987, Allan et al. 2003, Baxter et al. 2005). Thus, setting drift nets so that the net mouth protrudes above and captures terrestrial input at the water surface can provide useful information.

\section{Variation in macroinvertebrate abundances}

Our initial decomposition of variation in macroinvertebrate drift used unaggregated drift samples representing multiple times of day (3-8 periods) and channel positions ( 2 replicates). Much of the variance in unaggregated drift samples was attributable to diel periodicity and the dramatic increases in drift abundances that occur during crepuscular and low-light periods at night (Elliot 1970). The influence of diel periodicity also was evident in estimates of mean drift density and biomass collected during the day, which were half of the values collected at night (Fig. 2B, E). Drift diel periodicity raises several ecological and practical considerations when attempting to characterize the food supply of salmonids.

Evidence remains equivocal regarding the propensity of salmonids to forage from the drift during the night when low light may prevent effective sight feeding (Angradi and Griffith 1990, Johnson et al. 2012). The contribution that short crepuscular fluxes in drift make toward the total daily energy acquisition of drift-foraging salmonids is not well described (Railsback et al. 2005). Drift abundances estimated at the same location but at different times of the day can be highly correlated; e.g., the correlation between day and night drift abundances demonstrated by Allan and Russek (1985). A correlation between day and night drift abundances begs the question of whether investing sampling effort in capturing drift over an entire 24-h period necessarily provides a better description of salmonid food supplies. Monitoring drift nets during the night to ensure nets do not become clogged often is not practical for researchers working in remote areas or for collecting drift samples for rapid assessments of salmonid habitat that may be limited to a single site visit. Thus, sampling drift during daylight hours between crepuscular fluctuations offers the potential to reduce variance of drift abundance estimates, while capturing the relevant biological signal. 
Despite the relatively small channel widths and discharges over which our study was conducted (Table 1), lateral variation between replicate nets over a channel cross-section accounted for a substantial portion of variance in unaggregated samples of drift density and biomass (Table 2). Aggregating macroinvertebrates and volumes of water sampled by replicate drift nets reduced this source of sampling noise, and increased our ability to detect variation at target spatial scales. Drift nets also can be positioned to maximize the amount of discharge they capture at each cross-section, which may further reduce spatial variation among nets and may provide a more comprehensive description of the composition and abundances of macroinvertebrates entrained in the drift.

Variation in environmental conditions, such as changing weather patterns and fluctuations in discharge (Gibbins et al. 2007), also can trigger intentional (behavioral) and unintentional entry of macroinvertebrates into the drift and contribute to intraseasonal temporal variation. The summer season encompassed by this study consisted of fair and stable weather conditions, and all streams were near summer base flow when sampling commenced in late June. As other researchers studying drift have demonstrated, seasonal variation in macroinvertebrate drift abundances can be considerable (Shearer et al. 2002), and samples should be generalized only to the specific season or set of environmental conditions over which they were collected. However, low intraseasonal variation suggests that typical drift abundances can be characterized at seasonal scales over which weather and flow conditions are relatively consistent. Thus, sampling could be conducted, e.g., over the course of a summer, when an adequate supply of food is often critical if salmonids are to achieve positive growth (Boughton and Yedor 2007).

Variation in drift density and biomass among geomorphic units was also relatively low (Table 2), but made up 46 and $22 \%$ of the total variance in benthic density and biomass, respectively (Table 2). This contrast demonstrates how patchily distributed benthic macroinvertebrate communities become spatially homogenized in the drift. Drift entry may homogenize some of this spatial variability, but drift distances for macroinvertebrates in small streams are thought to be relatively short (e.g., 2-10 m; Allan and Feifarek 1989, Elliot 2003, Danehy et al. 2011). Thus, drift measurements within a reach would depend on the density and taxonomic composition of the benthic community in individual geomorphic channel units. In addition, drift abundances tend to vary with respect to channel unit characteristics, such as gradient or substrate composition (Hansen and Closs 2006). Based on this variability, distributing sampling effort among distinct geomorphic units may be beneficial if one is attempting to estimate a mean value of drift at the reach scale. However, care should be taken to provide adequate space between sets of drift nets to avoid depletion of downstream drift by upstream nets.

Estimates of $\mathrm{S}: \mathrm{N}$ and $\mathrm{CV}$ suggest that drift and benthic abundances can be estimated at the reach scale with a moderate level of precision (Table 3). S:N and CV are often used to describe the sampling precision of physical stream attributes measured as part of salmonid habitat monitoring and assessment protocols (Roper et al. 2002, 2010). Many physical stream attributes exhibit extremely high sampling precision at the reach scale and may have values of $\mathrm{S}: \mathrm{N}>$ 100 and CV as low as fractions of a percent. However, physical stream attributes also can exhibit lower precision than demonstrated here for macroinvertebrate drift when it is a product of observer inconsistency rather than temporal and spatial heterogeneity. Regardless, many physical attributes that lack sampling precision continue to be included routinely in stream habitat-monitoring protocols. In addition, mechanistic relationships between physical attributes and the performance of stream salmonids, such as a mechanistic model capable of predicting the effect of pool abundance on salmonid growth or survival, often are not well established (Fausch et al. 1988). In contrast, mechanistic approaches to describing how macroinvertebrate drift abundance directly influences salmonid growth rates are readily available (Van Winkle et al. 1998, Hayes et al. 2007, Weber et al. 2014).

\section{Drift sampling precision and effort}

Based on our variance estimates for drift biomass, CIs within $50 \%$ of the mean could be attained with 3 samples when variance is low and with 5 samples when variance is high. Similar precision for drift density, which had a higher variance than biomass would require 4 samples at low variance and 8 samples at the highest variance observed in our study. Previous investigators of the variability of drift have reported results similar to ours. For example, Neale et al. (2008) suggested that 10 drift samples would be needed to detect a $50 \%$ change in drift density. Allan and Russek (1985) estimated that $95 \%$ CIs within $50 \%$ of the mean were adequate for studies of drift and could be achieved with 6 to 7 samples. In a similar study, Shearer et al. (2002) recommended 5 samples.

These estimates of sampling effort may seem impractical, however a review of the range of values over which drift appears to influence salmonid performance indices can put our estimates of sampling effort in an applied context. For example, Rosenfeld and Raeburn (2009) showed that the growth rates of juvenile Coho Salmon (Oncorhynchus kisutch) were affected by measures of drift biomass that spanned orders of magnitude $\left(0.2-2 \mathrm{mg} / 100 \mathrm{~m}^{3}\right)$, and Urabe (2010) explained differences in salmonid biomass among streams where mean drift biomass ranged from 1 to $65 \mathrm{mg} / 100 \mathrm{~m}^{3}$. These examples highlight the potential magnitude of spatial variation in the drift and the magnitude of variation that is meaningful for fish. Similar examples can be found in controlled food manipulations designed to test the influence of variation in food supply on salmonid performance. Rosenfeld et al. (2005) showed that a 7-fold elevation of drift bio- 
mass was needed to produce an increase in the growth and survival of juvenile salmonids. Mechanistic models of salmonid foraging also support the idea that large differences in drift abundances are required to significantly affect salmonid performance. For example, Jenkins and Keeley (2010) had to manipulate drift by up to 20 -fold to significantly affect estimates of net energy intake in Cutthroat Trout (Oncorhynchus clarkii) habitat. In the context of this weight of evidence, our results suggest that differences in invertebrate drift abundance that matter to salmonids can be detected by a modest amount of sampling effort.

\section{Macroinvertebrate sampling recommendations}

Based on our investigation of variation in macroinvertebrate abundances, we think the following recommendations provide the most efficient and meaningful means of quantifying the food supply of stream salmonids. Our results suggest that estimates of biomass are more precise than estimates of density at the stream and reach scale, regardless of whether the collection method is based on drift or benthic samples. Biomass also may be a more descriptive measure of food abundance than density because biomass accounts for the size and number of prey items available. Estimates of abundance based on drift were more precise than estimates based on benthic sampling at targeted spatial scales. Drift provides a more direct measure of food for drift-feeding fish (Weber et al. 2014) because it includes emergent adult and terrestrial sources of macroinvertebrate prey. Our sampling recommendations take into account how drift could be collected efficiently as part of a regional habitat monitoring protocol in which individual stream reaches were sampled over a broad geographic extent with only 1 site visit/y.

Orienting drift nets over a channel cross-section in a manner that maximizes the proportion of the total discharge collected by each net may alleviate some of the variation caused by velocity gradients that create unequal drift distributions throughout the stream channel. Consideration also should be given to the duration and timing of drift collections within a day. Unless the aim is to sample over a 24-h period, crepuscular periods that induce dramatic behavioral spikes in drift abundance should be avoided. Daytime drift should be sampled for at least several hours to smooth out temporal fluctuations in abundance and taxonomic composition. Small-scale spatial variation also could be alleviated by pooling the contents and water volume sampled by replicate nets. If sampling is limited to a single visit, replication is best focused at the among-channel-unit scale. If multiple site visits are possible, then within-season replicates can be aggregated. This recommendation is supported by the relatively low variation in drift abundances observed between days and weeks. Last, because spatial variation in drift abundance within streams (at the scale of several kilometers) ap- pears to be relatively low, nearby reaches on the same stream could be used as replicates to increase drift sample sizes.

Factors affecting the distribution of macroinvertebrate communities in flowing waters operate at a level of complexity that probably is beyond our capability to describe fully. This complexity contributes to variation across space and time that demands careful consideration when attempting to make meaningful interpretations about the availability of macroinvertebrates as a food resource for salmonids. Describing salmonid habitat processes using a multiscaled framework will be an essential step toward the development of study designs that can be used to understand relationships between salmonid populations and habitat, and provide the necessary context for conservation and restoration planning. Our investigation of aquatic macroinvertebrate abundances is an example of how multiscaled research can be used in the development such study designs.

\section{ACKNOWLEDGEMENTS}

Author contributions: NW conducted the field work and laboratory processing of macroinvertebrate samples, data analysis, and wrote much of the manuscript. NB and CJ contributed substantially to the study design, analysis, and manuscript preparation.

Support for this project was provided by National Oceanic and Atmospheric Administration Fisheries and the Bonneville Power Administration project 2003-017. Ian Tattam, Seth White, and many others assisted with the field data collection that made this project possible. Additional thanks are owed to the faculty, staff, and students from the Watershed Sciences Department at Utah State University who were integral in the development, execution, and completion of this study. We also thank 2 anonymous referees and Associate Editor Russell Death for providing comments that greatly improved the quality of the finished manuscript.

\section{LITERATURE CITED}

Allan, J. D. 1978. Trout predation and the size composition of stream drift. Limnology and Oceanography 23:1231-1237.

Allan, J. D. 1987. Macroinvertebrate drift in a Rocky Mountain stream. Hydrobiologia 144:261-268.

Allan, J. D., and B. P. Feifarek. 1989. Distances travelled by drifting mayfly nymphs: factors influencing return to the substrate. Lournal of the North American Benthological Society 8:322330.

Allan, J. D., and E. Russek. 1985. The quantification of stream drift. Canadian Iournal of Fisheries and Aquatic Sciences 42: 210-215.

Allan, J. D., M. S. Wipfli, J. P. Caouette, A. Prussian, and J. Rodgers. 2003. Influence of streamside vegetation on inputs of terrestrial invertebrates to salmonid food webs. Canadian Journal of Fisheries and Aquatic Sciences 60:309-320.

Angradi, T. R., and J. S. Griffith. 1990. Diel feeding chronology and diet selection of rainbow trout (Oncorhynchus mykiss) in the Henry's Fork of the Snake River, Idaho. Canadian Journal of Fisheries and Aquatic Sciences 47:199-209. 
AREMP (Aquatic and Riparian Effectiveness Monitoring Program). 2013. Field protocol manual. Aquatic and Riparian Effectiveness Monitoring Program, Interagency Monitoring Program, Northwest Forest Plan. Pacific Northwest Regional Office, US Department of Agriculture Forest Service and Bureau of Land Management, Corvallis, Oregon. (Available from: https://reo.gov /monitoring/reports/watershed/2013.FieldProtocol.pdf)

Bates, D. M. 2010. lme4: mixed-effects modeling with R. R Project for Statistical Computing, Vienna, Austria. (Available from: http://lme4.0.r-forge.r-project.org/lMMwR/lrgprt.pdf)

Baxter, C. V., K. D. Fausch, and C. W. Saunders. 2005. Tangled webs: reciprocal flows of invertebrate prey link streams and riparian zones. Freshwater Biology 50:201-220.

Bonada, N., N. Prat, V. H. Resh, and B. Statzner. 2006. Developments in aquatic insect biomonitoring: a comparative analysis of recent approaches. Annual Review of Entomology 51:495-523.

Boughton, D. A., and R. Yedor. 2007. Stream temperature and the potential growth and survival of juvenile Oncorhynchus mykiss in a southern California Creek. Freshwater Biology 52:1353-1364.

Boyero, L. 2003. Multiscale patterns of spatial variation in stream macroinvertebrate communities. Ecological Research 18:365379.

Brittain, J. E., and T. J. Eikeland. 1988. Invertebrate drift-a review. Hydrobiologia 166:77-93.

Cada, G. F., J. M. Loar, and D. K. Cox. 1987. Food and feeding preferences of rainbow and brown trout in southern Appalachian streams. American Midland Naturalist 117:374-385.

Carter, J. L., and V. H. Resh. 2001. After site selection and before data analysis: sampling, sorting, and laboratory procedures used in stream benthic macroinvertebrate monitoring programs by USA state agencies. Iournal of the North American Benthological Society 20:658-682.

Danehy, R. J., R. B. Langshaw, S. D. Duke, and R. E. Bilby. 2011. Drift distance of macroinvertebrates throughout summer in headwater tributaries of the Calapooia River. Fundamental and Applied Limnology 178:111-120.

De Crespin De Billy, V., B. Dumont, T. Lagarrigue, P. Baran, and B. Statzner. 2002. Invertebrate accessibility and vulnerability in the analysis of Brown Trout (Salmo trutta L.) summer habitat suitability. River Research and Applications 18:533-553.

Downie, S. T. 2004. Stream channel measurement methods for core attributes. Coastal Watershed Planning and Assessment Program, California Department of Fish and Game, Fortuna, California. (Available from: http://coastalwatersheds.ca.gov /Portals/0/Assessment/docs/CWPAP_CoreAttributesMethods .pdf)

Elliot, J. M. 1970. Diel changes in invertebrate drift and the food of trout Salmo trutta L. Journal of Fish Biology 2:161-165.

Elliot, J. M. 1973. The food of brown and rainbow trout (Salmo trutta and S. gairdneri) in relation to the abundance of drifting invertebrates in a mountain stream. Oecologia 12:329347.

Elliot, J. M. 2003. A comparative study of the dispersal of 10 species of stream invertebrates. Freshwater Biology 48:1652-1668.

Fausch, K. D., C. L. Hawkes, and M. G. Parsons. 1988. Models that predict standing crop of stream fish from habitat variables: 1950-85. General Technical Report PNW-GTR-213. Pacific Northwest Research Station, US Department of Agriculture Forest Service, Portland, Oregon.
Flecker, A. S. 1992. Fish predation and the evolution of invertebrate drift periodicity: evidence from Neotropical streams. Ecology 73:438-448.

Folt, C. L., K. H. Nislow, and M. E. Power. 1998. Implications of temporal and spatial scale for Atlantic salmon (Salmo salar) research. Canadian Journal of Fisheries and Aquatic Sciences 55:9-21.

Gibbins, C., D. Vericat, R. J. Batalla, and C. M. Gomez. 2007. Shaking and moving: low rates of sediment transport trigger mass drift of stream invertebrates. Canadian Journal of Fisheries and Aquatic Sciences 64:1-5.

Hansen, E. A., and G. P. Closs. 2006. Temporal consistency in the long-term spatial distribution of macroinvertebrate drift along a stream reach. Hydrobiologia 575:361-371.

Hawkins, C. P., M. L. Murphy, N. H. Anderson, and M. A. Wilzbach. 1983. Density of fish and salamanders in relation to riparian canopy and physical habitat in streams of the Northwestern United States. Canadian Journal of Fisheries and Aquatic Sciences 40:1173-1185.

Hayes, J. W., N. F. Hughes, and L. H. Kelly. 2007. Process-based modelling of invertebrate drift transport, net energy intake and reach carrying capacity for drift-feeding salmonids. Ecological Modelling 207:171-188.

Heitke, J. D., E. J. Archer, and B. B. Roper. 2009. Effectiveness monitoring for streams and riparian areas: sampling protocol for stream channel attributes. PACFISH/INFISH Biological Opinion Effectiveness Monitoring Program (PIBO-EMP) Logan, Utah. (Available from: https://www.google.com/url?sa $=t \& r c t=j \& q$ $=\&$ esrc $=$ s\&source $=$ web\&cd $=1 \&$ ved $=0$ ahUKEwi_8Gk87fS AhWB3YMKHYcqBsEQFgghMAA\&url=https\%3A\%2F\%2Fwww .fs.fed.us\%2Fbiology\%2Fresources\%2Fpubs\%2Ffeu\%2Fpibo \%2Fpibo_2008_stream_sampling_protocol.pdf\&usg = AFQjC NErNNdUOYVHVzh-V0-UDsaFG5Fofg\&sig2=JLNOkLIHKrXqL HeJ3YkYsA\&cad=rja)

Hillman, T. W. 2006. Monitoring strategy for the Upper Columbia Basin. Upper Columbia Salmon Recovery Board, Bonneville Power Administration, and National Marine Fisheries Service, Silver Spring, Maryland. (Available from: http://www.ucsrb .org/Assets/Documents/Library/uc\%20monitoring\%20strategy \%20_08-01-06_.pdf)

Jenkins, A. R., and E. R. Keeley. 2010. Bioenergetic assessment of habitat quality for stream-dwelling cutthroat trout (Oncorhynchus clarkii bouvieri) with implications for climate change and nutrient supplementation. Canadian Journal of Fisheries and Aquatic Sciences 67:371-385.

Johnson, J. H., J. E. McKenna, and K. A. Douglass. 2012. Movement and feeding ecology of recently emerged steelhead in Lake Ontario tributaries. Journal of Applied Ichthyology 29: 221-225.

Kaufmann, P. R., P. Levine, E. G. Robison, C. Seeliger, and D. V. Peck. 1999. Quantifying physical habitat in wadeable streams. EPA/620/R-99/003. US Environmental Protection Agency, Washington, DC.

Larsen, D. P., P. R. Kaufmann, T. M. Kincaid, and S. N. Urquhart. 2004. Detecting persistent change in the habitat of salmonbearing streams in the Pacific Northwest. Canadian Journal of Fisheries and Aquatic Sciences 61:283-291.

Li, J. L., A. T. Herlihy, W. Gerth, P. R. Kaufmann, S. V. Gregory, S. N. Urquhart, and D. P. Larsen. 2001. Variability in stream 
macroinvertebrates at multiple spatial scales. Freshwater Biology 46:87-97.

Malmqvist, B. 2002. Aquatic invertebrates in riverine landscapes. Freshwater Biology 47:679-694.

Matthaei, C. D., D. Werthmüller, and A. Frutiger. 1998. An update on the quantification of stream drift. Fundamental and Applied Limnology 143:1-19.

Merritt, R. W., and K. W. Cummins (editors). 1995. An introduction to the aquatic insects of North America. $3^{\text {rd }}$ edition. Kendall/Hunt, Dubuque, Iowa.

Muller, K. 1974. Stream drift as a chronobiological phenomenon in running water ecosystems. Annual Review of Ecology and Systematics 5:309-323.

Naman, S. M., J. S. Rosenfeld, and J. S. Richardson. 2016. Causes and consequences of invertebrate drift in running waters: from individuals to populations and trophic fluxes. Canadian Journal of Fisheries and Aquatic Sciences 73:1292-1305.

Neale, M. W., M. J. Dunbar, I. Jones, and A. T. Ibbotson. 2008. A comparison of the relative contributions of temporal and spatial variation in the density of drifting invertebrates in a Dorset (U.K.) chalk stream. Freshwater Biology 53:1513-1523.

Nislow, K. H., C. L. Folt, and D. L. Parrish. 1999. Favorable foraging locations for young Atlantic salmon: application to habitat and population restoration. Ecological Applications 9:10851099.

Nislow, K. H., C. L. Folt, and M. Seandel. 1998. Food and foraging behavior in relation to microhabitat use and survival of age- 0 Atlantic salmon. Canadian Journal of Fisheries and Aquatic Sciences 55:116-127.

Palmer, M. A., C. C. Hakenkamp, and K. Nelson-Baker. 1997. Ecological heterogeneity in streams: why variance matters. Iournal of the North American Benthological Society 16:189202.

Parsons, M., M. C. Thoms, and R. H. Norris. 2003. Scales of macroinvertebrate distribution in relation to the hierarchical organization of river systems. Iournal of the North American Benthological Society 22:105-122.

Peck, D. V., Hughes, R. M., A. T. Herlihy, B. H. Hill, P. R. Kaufmann, D. J. Klemm, J. M. Lazorchak, F. H. McCormick, S. A. Peterson, P. L. Ringold, T. Magee, and M. R. Cappaert. 2006. Environmental Monitoring and Assessment ProgramSurface Waters Western Pilot Study: field operations manual for wadeable streams. EPA/620/R-06/003. Office of Research and Development, US Environmental Protection Agency, Washington, DC.

Poff, N. L., J. D. Olden, N. K. M. Vieira, D. S. Finn, M. P. Simmons, and B. C. Kondratieff. 2006. Functional trait niches of North American lotic insects: traits-based ecological applications in light of phylogenetic relationships. Journal of the North American Benthological Societv 25:730-755.

Poff, N. L., and J. V. Ward. 1991. Drift responses of benthic invertebrates to experimental streamflow variation in a hydrologically stable stream. Canadian Journal of Fisheries and Aquatic Sciences 48:1926-1936.

Rader, R. B. 1997. A functional classification of the drift: traits that influence invertebrate availability to salmonids. Canadian Journal of Fisheries and Aquatic Sciences 54:1211-1234.
Railsback, S. F., B. C. Harvey, J. W. Hayse, and K. E. LaGory. 2005. Tests of theory for diel variation in salmonid feeding activity and habitat use. Ecology 86:947-959.

Roper, B. B., J. M. Buffington, S. Bennett, S. H. Lanigan, E. Archer, S. T. Downie, J. Faustini, T. W. Hillman, S. Hubler, K. Jones, C. Jordan, P. R. Kaufmann, G. Merritt, C. Moyer, and A. Pleus. 2010. A comparison of the performance and compatibility of protocols used by seven monitoring groups to measure stream habitat in the Pacific Northwest. North American Journal of Fisheries Management 30:565-587.

Roper, B. B., J. L. Kershner, E. Archer, R. C. Henderson, and N. Bouwes. 2002. An evaluation of physical stream habitat attributes used to monitor streams. \ournal of the American Water Resources Association 38:1637-1646.

Rosenfeld, J. S., T. Leiter, G. Lindner, and L. Rothman. 2005. Food abundance and fish density alters habitat selection, growth, and habitat suitability curves for juvenile coho salmon (Oncorhynchus kisutch). Canadian Journal of Fisheries and Aquatic Sciences 62:1691-1701.

Rosenfeld, J. S., and E. Raeburn. 2009. Effects of habitat and internal prey subsidies on juvenile coho salmon growth: implications for stream productive capacity. Ecology of Freshwater Fish 18:572-584.

Shearer, K. A., J. W. Hayes, and J. D. Stark. 2002. Temporal and spatial quantification of aquatic invertebrate drift in the Maruia River, South Island, New Zealand. New Zealand Journal of Marine and Freshwater Research 36:529-536.

Tippets, W. E., and P. B. Moyle. 1978. Epibenthic feeding by Rainbow Trout (Salmo gairdneri) in the McCloud River, California. Journal of Animal Ecology 47:549-559.

Urabe, H., M. Nakajima, and M. Torao. 2010. Evaluation of habitat quality for stream salmonids based on a bioenergetics model. Transactions of the American Fisheries Society 139:1665-1676.

Van Winkle, W., H. I. Jager, S. F. Railsback, B. D. Holcomb, T. K. Studley, and J. E. Baldrige. 1998. Individual-based model of sympatric populations of brown and rainbow trout for instream flow assessment: model description and calibration. Ecological Modelling 110:175-207.

Waters, T. F. 1962. Diurnal periodicity in the drift of stream invertebrates. Ecology 43:316-320.

Waters, T. F. 1972. The drift of stream insects. Annual Review of Entomology 17:253-272.

Weber, N. P., N. Bouwes, and C. E. Jordan. 2014. Estimation of salmonid habitat growth potential through measurements of invertebrate food abundance and temperature. Canadian Journal of Fisheries and Aquatic Sciences 71:1158-1170.

Whittier, T. R., R. M. Hughes, and D. P. Larsen. 1988. Correspondence between ecoregions and spatial patterns in stream ecosystems in Oregon. Canadian Journal of Fisheries and Aquatic Sciences 45:1264-1278.

Wiens, J. A. 1989. Spatial scaling in ecology. Functional Ecology 3:385-397.

Wipfli, M. S., and C. V. Baxter. 2010. Linking ecosystems, food webs, and fish production: subsidies in salmonid watersheds. Fisheries 35:373-387.

Zar, J. H. 1999. Biostatistical analysis. $4^{\text {th }}$ edition. Prentice Hall, Upper Saddle River, New Jersey. 